\title{
A prática do ensino de inglês: desenvolvimento de competências ou legitimação das crenças? Um estudo de caso
}

\author{
Elaine Fernandes Mateus \\ Telma Nunes Gimenez \\ Denise Ismênia Bossa Grassano Ortenzi \\ Simone Reis \\ Universidade Estadual de Londrina
}

\begin{abstract}
Although most of the studies in the field of teacher education advocate that the practicum is the main source for the acquisition of the knowledge and skills required by good teachers (Richards e Crookes, 1988; Pimenta, 1997; Kulcsar, 1998; Piconez, 1998), research adopting a socialization framework questions the full impact of this stage of professional development. The study reported here intended to investigate the impact of the practicum, according to EFL student teachers' own perspectives. They were enrolled in a university teacher education course in Brazil, through which they were exposed to new educational experiences aimed at contributing to better informed pedagogical practices and to the development of the knowledge base necessary for conscious professional work. Using semi-structured interviews and observation reports as the main source of data, the analysis revealed that although the informants acknowledged the importance of the teaching practice experiences, there were limitations of their influence on developing the process of learning to teaching within a critical reflection mode (Tabachnick e Zeichener, 1991). The study also revealed that the student teachers were at elementary stages of professional development, according to Furlong \& Maynard's (1995) classification.
\end{abstract}

A Prática do Ensino de Inglês (PEI) é uma das disciplinas que compõem o currículo do último ano dos alunos de Letras Anglo de uma universidade pública no norte do Paraná. Durante esse período, os futuros professores são expostos a novas experiências educacionais que pretendem contribuir para uma prática pedagógica informada e desenvolver bases analíticas para o trabalho profissional consciente. Embora boa parte dos estudos nessa área assegurem que a experiência do estágio é a principal fonte para a aquisição de conhecimento e habilidades essenciais ao bom professor (Richards e Crookes, 1988; Pimenta, 1997; Kulcsar, 1998; Piconez, 1998), estudos que se fundamentam na perspectiva da socialização questionam o impacto da prática de ensino no processo de aprender a ensinar de maneira informada (Lortie, 1975; Feiman-Nemser e Buchmann, 1989; Freeman, 1992). Nesse sentido, o relato apresentado busca discutir o impacto desse componente na formação dos alunos de Letras, segundo suas próprias perspectivas. Para tanto, procedemos a análise de entrevistas semi-estruturadas, bem como de relatórios dos estágios. Os resultados apontam que, embora os futuros professores enalteçam esse componente curricular, há limitações do impacto da PEI sobre o processo de aprender a ensinar 
reflexivamente, numa perspectiva crítica (cf. Tabachnick e Zeichner, 1991). A análise revela ainda alunos professores em estágios elementares de seu desenvolvimento profissional, segundo a classificação de Furlong e Maynard (1995).

\section{Introdução}

É comum tomarmos por certa a relevância da Prática de Ensino no processo de formação de professores. Quem de nós que trabalhamos com alunos nesse período já não os ouviu dizendo: "O estágio foi a melhor coisa do curso porque afinal consegui pôr em prática e entender muito do que sempre me foi dito"? Ou então: "Por que temos tão poucas horas de prática se essa se configura como a essência do curso de licenciatura"? Vistos de forma simples e sem uma análise mais criteriosa é realmente difícil contestar tais argumentos e mais; é impossível não afirmar que toda prática de estágio é componente fundamental no processo de formação dos futuros professores. E de fato, a Prática de Ensino deveria constituir-se no momento de síntese do curso de formação de professores, buscando não apenas integrar teoria e prática, mas assumindo a responsabilidade de formar profissionais conscientes de sua atuação social, capazes de contribuir para a mudança da realidade em que vivem.

Há na literatura específica um número considerável de trabalhos que exploram a influência da prática de estágio sobre a formação do futuro professor. Para alguns pesquisadores, esta é, sem dúvida, a principal oportunidade que os alunos professores têm para adquirir, desenvolver e produzir conhecimentos e habilidades práticas que lhes possibilitem desempenho eficaz quando professores (e.g. Richards e Crookes, 1988; Pimenta, 1997; Piconez, 1998).

Por outro lado, os estudos que se fundamentam na perspectiva da socialização vão além e questionam não somente o impacto do componente prático, mas dos próprios cursos de formação de professores no processo de aprender a ensinar. Nessa corrente encontram-se estudos que, baseados em Lortie (1975), entendem que o crédito concedido à prática deve ser limitado devido ao seu caráter restritivo: trabalho com um único professor colaborador; pouco acesso a diferentes técnicas de ensino; pouca influência do professor colaborador sobre o aluno mestre, entre outros. Em conseqüência desta estrutura, o autor afirma que o estágio não desafia a natureza rotineira da aprendizagem por observação ${ }^{11}$. No entanto, Lortie reconhece que a prática informada, capaz de avaliar o ensino e de desenvolver bases analíticas para o trabalho profissional, só pode acontecer por meio de experiências de socialização formal que desafiem as experiências trazidas pelos alunos professores.

Da mesma forma, Freeman (1992) acredita que a educação do professor é uma forma pouco significativa de intervenção, a menos que lide com as concepções de ensino e aprendizagem trazidas pelos alunos professores. O autor entende que somente a partir da

\footnotetext{
${ }^{1}$ Esse termo é empregado por Lortie (1975) para designar o processo de socialização mais amplo, que tem início no momento em que entramos em contato com a cultura escolar e que nos familiariza com as tarefas do professor.
} 
articulação do conhecimento tácito o futuro professor poderá vir a conceituar o ensino de forma diferente daquela feita quando era apenas aluno. Isso é o que Feiman-Nemser e Buchmann (1989, p. 136) chamam de transição para o pensamento pedagógico, que consiste em "pensar sobre o que os professores fazem em termos do que os alunos podem e devem aprender". Portanto, mesmo autores que põem em xeque o impacto da prática de ensino reconhecem que este componente do processo de educação formal pode colaborar para o amadurecimento de perspectivas analisadas, até então, somente sob a ótica de aluno.

Nossas experiências como formadoras de professores têm nos revelado as limitações do impacto que se pretende ter sobre os futuros profissionais, especialmente se analisado sob a ótica do "aprender a ensinar reflexivamente", atingindo o domínio crítico dessa reflexão (cf. Tabachnick e Zeichner, 1991), no qual critérios éticos e morais devem ser incorporados. Com base na necessidade de tornar claros alguns dos aspectos da multifacetada tarefa de aprender a ensinar, esse estudo pretende analisar o impacto da prática de ensino sobre o desenvolvimento profissional de alunos professores, tomando como elemento de análise suas próprias percepções. A questão que se coloca, portanto, é qual o impacto da prática de ensino de Inglês no contexto investigado para a formação crítico-reflexiva das alunas em foco. Ter as percepções das alunas professoras como ponto de partida para analisar e discutir seu processo de formação permitirá trazer à tona os estágios de desenvolvimento nos quais se encontram ao mesmo tempo em que possibilitará compreender a relação entre o impacto que desejamos como formadores e aquele que elas esperam como futuras professoras.

Assim, iniciamos esse relato apresentando os referenciais teóricos que serviram como pano de fundo para a análise e discussão dos dados. Em seguida, contextualizamos a pesquisa dentro de um estudo maior, a partir do qual os dados foram derivados. A apresentação dos resultados dá destaque ao impacto da prática de estágio, segundo os futuros professores, tendo em mente as implicações da mesma para a formação de profissionais críticos e autônomos. Finalmente, traçamos considerações acerca desse componente curricular, levantando questões sobre sua relevância para a formação de professores.

\section{Fundamentação teórica}

Para discutirmos os dados tomaremos como base os referenciais teóricos do modelo de formação reflexiva (cf. Tabachnick e Zeichner, 1991) e dos estágios de desenvolvimento dos professores (cf. Fuller e Bown, 1975; Furlong e Maynard, 1995).

A concepção de prática reflexiva proposta pelo filósofo americano John Dewey, no início do século, influenciou outros educadores contemporâneos, dentre os quais Tabachnick e Zeichner (1991) que distinguem diferentes tipos de reflexão com base na dicotomia entre o pensamento cotidiano, rotineiro e o pensamento reflexivo. Assim, eles apresentam os domínios:

- técnico, que revela preocupações com a eficiência dos meios ou técnicas utilizadas para se atingir os fins, normalmente estabelecidos por outras pessoas e que, por sua vez, ficam sem serem examinados;

- prático, no qual predomina a necessidade de explicar e esclarecer os pressupostos e predisposições que norteiam as atividades de ensino e de avaliar a adequação dos 
objetivos, bem como de que forma eles foram alcançados. Há, neste sentido, a consideração dos fins educacionais;

- crítico, que incorpora critérios éticos e morais no discurso da prática. As questões centrais consideram o benefício dos objetivos, atividades e experiências educacionais diante dos conceitos de eqüidade, justiça e realização concreta para todos os alunos.

Ortenzi (1997) argumenta que reflexões no domínio crítico, que idealmente deveria ser alcançado pelos professores, são possíveis somente na medida em que os [futuros] profissionais percebem a dimensão política de sua prática. Contudo, refletir sobre o ensino com base na aprendizagem de conceitos que extrapolem as limitações da nossa cultura educacional celular ${ }^{2}$ (Lortie, 1975) exige amadurecimento de questões mais elementares, conforme esclarecem Fuller e Bown (1975).

Baseados em uma revisão de aproximadamente trezentos trabalhos, entre os quais alguns empíricos, Fuller e Bown (1975) conceituaram fases no desenvolvimento dos alunos professores e levantaram a hipótese de que as preocupações são seqüenciais e cumulativas. Assim, antes que o futuro professor atinja a maturidade profissional e pense no ensino em termos do seu impacto sobre os alunos e seu crescimento - processo que Feiman-Nemser e Buchmann (1989) chamam de transição para o pensamento pedagógico - ele passa por fases reveladas por preocupações características.

Outro estudo bastante representativo na área dos estágios do desenvolvimento de professores em pré-serviço é o de Furlong e Maynard (1995) por tentar expandir a noção seqüencial proposta anteriormente. Para estes pesquisadores, o desenvolvimento do aluno mestre não se dá de forma linear, mas simultânea. Com base em dados coletados em cinco escolas públicas de ensino fundamental, com alunos do curso de educação primária, os pesquisadores elaboraram cinco categorias: (1) idealismo inicial; (2) sobrevivência pessoal; (3) lidando com dificuldades; (4) atingindo a planície e (5) seguindo em frente.

$\mathrm{Na}$ fase do idealismo inicial, os resultados de Furlong e Maynard corroboram a descrição de Fuller e Bown (1975). Também seus alunos professores identificaram-se muito mais com os alunos do que com os professores colaboradores e expressaram uma imagem idealizada do tipo de professor que gostariam de ser - caloroso, amigo, entusiasmado, atencioso e popular -, do tipo de relacionamento que gostariam de manter com seus alunos - amigável, mas respeitoso -, bem como da atmosfera alegre, calorosa e de cooperação que gostariam de criar em suas salas de aula.

A crença de que o relacionamento pessoal do aluno professor com seus alunos é fator predominante para sua eficácia profissional, é vista por Furlong e Maynard como simplista e é rapidamente ofuscada pelas realidades da sala de aula, assim que tem início a prática de ensino. Neste momento, surgem as preocupações com a sobrevivência pessoal, que Furlong e Maynard caracterizam como o processo de ajustar-se às rotinas e expectativas do professor colaborador, de ser visto e respeitado como professor responsável pela turma e de conseguir o controle da sala de aula. Ajustar-se às rotinas significava, para muitos dos alunos professores estudados por Furlong e Maynard, copiar o estilo do professor, especialmente no que diz respeito ao seu relacionamento com os alunos. Fazendo isto, eles

\footnotetext{
${ }^{2}$ A partir de uma perspectiva sociológica, Lortie (1975) esclarece que o crescimento da demanda escolar seguiu sempre um modelo de agregação de salas de aula, ou células, construídas como auto-suficientes. Decorrente disto, ainda hoje escolas são organizadas de forma que cada professor desenvolva um trabalho isolado, independente dos demais colegas.
} 
imaginavam não quebrar a rotina e ter a chance de conduzir seu trabalho mais suavemente. Consequentemente, a imagem de professor idealizada anteriormente cedia espaço ao tipo de professor que eles achavam que deveriam ser a fim de sobreviverem inicialmente. A necessidade de serem vistos e respeitados como professores da turma relaciona-se de forma direta com as questões relativas ao controle da disciplina em sala de aula. As preocupações mais recorrentes estão em preparar atividades que mantenham os alunos trabalhando e em desenvolver procedimentos que mantenham-nos em seus lugares. Nesta fase, os alunos professores temem desviarem-se dos planos elaborados e sentem-se extremamente frustrados quando suas idéias não dão certo e quando não conseguem controlar $\mathrm{o}$ comportamento dos seus alunos.

A fase seguinte surge a partir da segunda ou terceira semana quando os alunos professores passam a ver as dificuldades da sala de aula e a se preocupar mais com seu comportamento profissional. Neste período, eles procuram se estabelecer como professores, normalmente replicando aquilo que eles consideram ser o comportamento de um professor. Furlong e Maynard (1995, p. 82) apontam que os alunos professores "agem como professores, mas sem necessariamente compreender os propósitos subjacentes ou as implicações daquelas ações". Além disso, preocupam-se em impressionar o professor colaborador e, especialmente o professor supervisor, responsável pela avaliação de sua competência profissional. Os alunos professores estudados revelaram que, apesar dos professores colaboradores os encorajarem a ver esta como uma experiência de aprendizagem, a maior preocupação estava em 'fazer a coisa certa' para ser aprovado na disciplina. Devido à pouca compreensão que os alunos professores tinham dos pressupostos que fundamentavam suas ações, eles tentavam impressionar por meio de estratégias de ensino e de manejo de sala, preparando explicações claras e dinâmicas de grupo que os mantivessem no controle da disciplina. Foi bastante característica nesta fase a utilização de materiais extras que deixassem os alunos ocupados.

Após terem adquirido confiança em seu conhecimento pedagógico geral, os futuros professores atingem a planície. Neste estágio, eles sentem-se como 'verdadeiros professores'. Contudo, a não compreensão dos pressupostos que fundamentam suas práticas não lhes permite ainda perceber a relação entre o ensino e a aprendizagem dos alunos. A maioria dos alunos professores estudados por Furlong e Maynard, ao sentirem-se mais confiantes e relaxados, passaram a apresentar planos e avaliações menos elaborados e a perder o entusiasmo em tentar novas estratégias e atividades. Apesar de 'verdadeiros professores', neste estágio os alunos professores não se mostraram capazes de desenvolver atividades voltadas à aprendizagem de seus alunos.

Para que os alunos sigam em frente, ou seja, consigam analisar sua prática criticamente, compreender as responsabilidades de ser um educador, desenvolver as habilidades do pensamento pedagógico e fazer assim a transição para o papel de professor, é necessário que haja intervenções por parte dos professores supervisores voltadas diretamente para os propósitos e implicações da educação. Outros estudos mostram que sem desafio e suporte, os alunos professores dificilmente atingem este estágio. Furlong e Maynard (1995) argumentam que na fase do seguindo em frente os alunos professores eram levados a refletir sobre as implicações das atividades em termos da aprendizagem de seus alunos. Não sem resistência, muitos sentiam-se frustrados e até mesmo deprimidos, uma vez que este processo implica em questionar as próprias crenças, muitas já bastante arraigadas, sobre ensino e aprendizagem. 


\section{O estudo}

O estudo que apresentamos agora faz parte de um projeto de pesquisa intitulado "Aprendendo a ensinar Inglês: um estudo longitudinal com estagiários do curso de Letras". Esse projeto foi motivado pela necessidade que sentíamos de verificar a interação entre o conhecimento gerado pelas experiências socializadoras e o conhecimento gerado pelas experiências educacionais na universidade em que atuamos. Tendo como referenciais teóricos estudos que reconhecem a importância de experiências anteriores aos cursos de formação de professores, bem como estudos que enfatizam a importância de se entender as ações do professor do ponto de vista de seu sistema de crenças e valores, esse projeto teve início em 1999, ano em que os dados foram coletados com 14 alunos do $4^{\circ}$ e último ano do curso de Letras Anglo de uma universidade pública no norte do Estado do Paraná. À época da coleta dos dados, os alunos professores desse curso tinham em seu currículo 68 horas de prática do ensino de Inglês concentradas no último ano. Essa carga horária era distribuída entre observação de aulas em escolas públicas, confecção de relatórios de observação e de regência, planejamento supervisionado e direção de classe. O conjunto de dados coletados incluí autobiografia, inventário de crenças aplicado no início e final do ano letivo, gravações em áudio de sessões de encontros para supervisão de estágio, relatórios de observação de aulas, relatórios de estágio e entrevistas semi-estruturadas.

A análise seguinte concentra-se nos dois últimos instrumentos, uma vez que eles revelam com maior propriedade as percepções dos alunos sobre seu desenvolvimento durante a prática de ensino. O relatório de estágio apresentava-se como um dos componentes da avaliação da disciplina Prática do Ensino de Inglês: Estágio Supervisionado e tinha o propósito de sistematizar as reflexões feitas durante as 28 horas de regência. Era objetivo também do relatório permitir uma reflexão acerca do desenvolvimento profissional dos alunos professores e da interação entre suas experiência formais e informais. Por sua vez, as entrevistas semi-estruturadas conduzidas ao final do ano letivo pretendiam suscitar suas percepções a respeito do estágio, bem como do componente teórico do curso.

O presente relato concentra-se em 2 das 14 alunas professoras envolvidas no projeto, que serão identificados pelos nomes de Adriana e Berenice. Tal escolha deu-se de forma aleatória, tendo em mente que os resultados apresentados pretendem melhor compreender o que os acontecimentos significam para os envolvidos nesse meio sócioeducacional.

\section{Os resultados}

Os resultados dos alunos professores serão apresentados separadamente, tendo como ponto de partida suas próprias percepções acerca do impacto da prática de estágio, e como referencial as implicações desse componente curricular para a formação de profissionais críticos e autônomos. 


\section{Adriana}

Adriana era uma aluna cujo ingresso no curso de Letras deu-se pelo sonho de aprender e ensinar Inglês. Tendo sido forçada a abandonar os estudos da língua em dois outros momentos de sua vida por motivos de ordem material, ela via na universidade pública a chance de aprender inglês. Contudo, o foco na gramática trouxe dificuldades extras durante o curso e por várias vezes ela dizia achar o ensino que havia recebido complicado, difícil e desestimulante. Contudo, casada e grávida de seu primeiro filho, foi sempre uma aluna responsável e pontual em suas tarefas durante o curso. Diferente de muitos de seus colegas, Adriana havia feito magistério e tinha alguma experiência de sala de aula. Há alguns anos trabalhando com crianças no ensino primário, ela tinha crenças bem marcadas quanto ao seu papel. Para ela:

O bom professor é aquele que tem um relacionamento amigável com seus alunos, deve ser dinâmico, flexível e ter senso de humor.

Consequentemente, acreditava que:

É preciso ensinar a matéria de uma forma diferente, dinâmica, quebrar a rotina.

Assim como a grande maioria dos alunos mestres, também Adriana afirma ter sido a prática de ensino um momento importante em seu processo de formação. Segundo ela relata em seu relatório de estágio:

Ao final do meu trabalho na prática de estágio, concluo que para mim a experiência em sala de aula foi muito válida e rica, no sentido de uma reflexão sobre a atuação do professor perante o processo de ensinoaprendizagem, e defendo a questão de que cabe ao professor o sucesso ou fracasso de seu aluno.

Falar que a prática de ensino permitiu uma reflexão sobre a atuação do professor nos leva a imaginar que Adriana tenha sido capaz de entender sua prática sob a perspectiva do aluno, ou seja, tenha se tornado capaz de refletir criticamente sobre as responsabilidades de um educador. Contudo, quando questionada durante a entrevista a respeito das certezas e dúvidas adquiridas a partir do estágio, ela comenta:

no geral eu posso dizer assim que eu fui muito feliz no meu estágio, e tanto que gerou até assim um clima de amizade mesmo entre os alunos, né, que eu já sentia como se fosse minha própria sala de aula, né. Então, depois que eu saí, como eu moro num local próximo à escola, às vezes eu encontro com os alunos, né, fora da escola "ô professora, você não vai voltar dar aula pra gente?" e tal. Então, eu sinto assim que houve um envolvimento, que os alunos gostaram. Eu sai satisfeita por mais que sempre tem alguma coisa que dá pra ser melhorada (...) Então, eu acredito que eu consegui desenvolver um trabalho, eu criei um clima de envolvimento com os alunos sim. 
Aqui é possível notar que apesar do impacto testemunhado pela aluna professora, sua análise não avança para além de questões centradas no ensino e nunca na aprendizagem. Ela avalia, de forma simplista, o sucesso de sua prática pelo grau de amizade que criou com os alunos. Embora reconheça a existência de limitações e dificuldades em sua prática é incapaz de compreender as complexidades do ensino. Se voltarmos aos estágios descritos anteriormente por Furlong e Maynard (1995), veremos que ela se encontra em uma etapa ainda bastante inicial, preocupada em lidar com as dificuldades e em avaliar a eficácia dos meios utilizados para alcançar seu objetivo pessoal: o de manter um relacionamento amigável e despertar o interesse dos alunos.

Em outros momentos da entrevista Adriana também demonstra não ser capaz de refletir sobre sua atuação pedagógica para além do nível técnico. Se por um lado esse aspecto pode ser considerado elemento essencial para uma prática bem sucedida, por outro não parece suficiente para a construção de um conjunto de conhecimentos voltados à transformação da ação docente. Todas as vezes em que era indagada sobre sua prática ela a analisava em termos do que fazer e de como fazer:

A professora levava letra de música, levava algum outro tipo de material que envolvesse mais, os alunos trabalhavam em grupos e eu percebia o envolvimento deles na aula. Então, eu fiquei imaginando como eu poderia trabalhar no meu estágio. (...) Mas a gente percebe que quando você chega na sala de aula com um jogo, com alguma coisa que interessa é bem diferente a aula, né, o envolvimento. (...) ai eu continuei pensando o que fazer nas outras aulas pra que continuasse aquele interesse, né, e eu percebi o seguinte: quando é desenvolvida a aula dessa forma, com dinâmicas, com materiais extras, eu conseguia um envolvimento grande; quando eu pedia pra usar o livro...

A experiência de estágio descrita por Adriana como válida e rica parece ter servido para confirmar e tornar mais fortes as crenças trazidas e apresentadas desde o início da prática, como as que mostramos anteriormente. Nesse sentido, o impacto por ela mencionado se distancia certamente daquele desejado por formadores de professores que entendem esse como um momento de contribuir para o desenvolvimento de uma prática pedagógica informada e consciente que permita a revisão de conhecimentos e crenças desenvolvidos no período da aprendizagem por observação.

Além disso, a experiência da prática do ensino de inglês parece contribuir de sobremaneira para confirmação das escolhas, como mostra o seguinte trecho:

... dentro desse estágio que eu tive realmente a certeza da área que eu quero trabalhar porque antes eu não tinha certeza se era inglês, se era português. Mas eu acredito que dentro desse estágio eu consegui realizar um trabalho bom e tenho vontade de trabalhar nessa área, mais do que com o português.

Essa certeza parece revelar uma identidade tardia com o curso, o que certamente traz conseqüências para a construção de imagens pessoais que dêem conta de compreender e lidar com as complexas realidades das salas de aula (Ortenzi, Mateus e Reis, 1996). 


\section{Berenice}

A experiência de Berenice como aprendiz da língua desde muito cedo em academias fez com que ela se apaixonasse pelo inglês. Seu sucesso como aprendiz e o apoio de uma de suas professoras a motivou para o ingresso no curso. $\mathrm{Na}$ universidade as sensações ficam todas misturadas, pois há medo, insegurança, entusiasmo, realizações $e$ decepções. Mesmo assim, Berenice repete sempre a certeza de querer ser professora de Inglês. Contudo, sem experiência anterior alguma de sala de aula, as crenças de Berenice quanto ao papel do professor vinham de suas vivências como aprendiz de língua, como mostra um trecho de sua entrevista:

Olha, eu me via assim como as minhas professoras eram no ginásio, é... seguia o livro didático ali tal, é... qualquer coisa mandava o aluno pra diretoria, aquela coisa bem autoritária, bem tradicional mesmo, né.

Ser autoritária e tradicional são características de sua prática contra as quais ela parece lutar o tempo todo. Na verdade, essa é antes uma crença que concebe o professor como autoridade responsável pelo estabelecimento e manutenção da ordem em sala de aula (Feiman-Nemser e Floden, 1986). Assim, contrariando os resultados de alguns estudos, Berenice iniciou sua prática menos preocupada em estabelecer um relacionamento amigável e caloroso com seus alunos e mais voltada para o tipo de professora que deseja ser. Desta forma, ela relata que no início:

... eu me peguei muitas vezes realmente mandando o aluno calar a boca, realmente querendo pôr o aluno pra fora da sala. (...) eu não gostaria de dar aula como eu tive aula; eu queria ser aquela professora amiga, que fosse aquela aula gostosa, descontraída.

E é nesse aspecto que Berenice vê o impacto do estágio sobre sua formação. É exatamente no que diz respeito ao seu comportamento como professora, nas suas atitudes e posturas com relação aos alunos e ao ensino propriamente dito. Segundo ela própria afirma durante a entrevista:

...logo que eu comecei dar aula eu queria ser aquela professora bem tradicional, autoritária e de repente eu me vi e eu trabalhei assim olha até a metade do estágio. Aí, eu comecei a repensar e até hoje eu repenso nisso, eu fico pensando nisso, porque eu tô querendo criar um modelo de professor como eu gostaria de ser como modelo de professor. Então, eu fico tentando ver os meus professores, os que eu tive, os que eu tô tendo ainda esse ano, como eles dão aula, o que eu gosto, o que eu não gosto, sabe, eu tô tentando pegar um pedacinho de cada e adaptar em mim.

Sem dúvida todo o esforço de Berenice estava em desenvolver-se como professora em termos daquilo que ela imaginava que deveria ser. Em momento algum ela se refere ao estágio como forma de considerar o que e como os alunos aprendem. Apesar do 
reconhecido impacto atestado por ela, Berenice continuou a 'ver o professor como aluno', "tentando pegar um pedacinho de cada um" para compor seu personagem e não foi capaz de 'ver-se como professora' responsável por promover a aprendizagem de seus alunos. Em todas as suas falas está fortemente presente a crença de que

o professor é o responsável por trazer o aluno para sua aula e fazer com que ele goste da sua disciplina, despertar o interesse e a atenção dos alunos, mostrar que aquilo que está sendo ensinado é importante.

Como vemos, o foco de suas reflexões está no professor. Embora seja fundamental que o futuro professor aprenda a detectar sinais de compreensão e confusão na aprendizagem dos alunos e que seja estimulado a implementar suas preocupações nesta área, Berenice limita suas reflexões ao papel do professor, tomando por certo que afinidades pessoais levam diretamente ao "gosto" pela disciplina e, consequentemente, à quase misteriosa aprendizagem. Nesse sentido, ela se preocupa muito em comportar-se como professora, mas sem necessariamente compreender os propósitos subjacentes ou as implicações de suas ações. Esse visão ingênua de sua prática a coloca em um estágio bastante elementar de seu desenvolvimento profissional que não permite uma reflexão mais crítica de seu papel social. Mais grave, a prática que deveria servir como instrumento para a construção de um conhecimento criticamente informado, que permitisse à Berenice pensar sobre suas ações pedagógicas em termos do que os alunos podem e devem aprender, serviu para legitimar as experiências trazidas para esse contexto. As certezas de Berenice após quase um ano de socialização formal são as de que gostando dela os alunos gostarão de inglês, como mostra mais um trecho da entrevista:

A certeza que eu tenho é que é isso mesmo que eu quero: ser professora. (...) TÔ com muita expectativa, apesar que o governo tá fazendo essa bagunça com a educação, né, boas expectativas. Quero ser uma excelente professora. Quero que meus alunos gostem de mim, gostem da minha matéria, vou trabalhar pra isso. E essa é minha principal certeza: de que tô no caminho certo

A expectativa de promover o gosto pela disciplina como forma, ou como "o caminho certo" para uma prática bem sucedida simplifica em muito seu papel de educadora, inserida em um contexto carregado de responsabilidades sociais.

\section{Algumas considerações}

Os dados apresentados apontam que embora todos os futuros professores enalteçam a relevância da prática de estágio, há limitações do impacto desse componente curricular sobre o processo de aprender a ensinar reflexivamente, numa perspectiva crítica (cf. Tabachnick e Zeichner, 1991). A análise revela também que tanto Adriana como Berenice encontram-se ainda em estágios elementares de seu desenvolvimento profissional, segundo a classificação de Furlong e Maynard (1995). Ambas transitam entre os estágios de sobrevivência pessoal e lidando com as dificuldades. 
A caracterização das etapas alcançadas pelas duas estagiárias revela que a prática de ensino teve um impacto sobre o processo de formação de Adriana e Berenice, embora em graus diferenciados dos idealizados pelos supervisores, qual seja o de ser um "rito de passagem". Talvez como conseqüência da forma como os estágios estão estruturados e pela própria ambigüidade de papéis do aluno professor, a experiência parece ter se configurado mais como legitimação das práticas adotadas rotineiramente pelos professores regentes. Em conseqüência, este estudo nos mostra que para as duas alunas professoras, mais importante do que tornarem-se conscientes do papel social do professor de inglês, capaz de confrontar seus conhecimentos e de considerar a qualidade e o valor daquilo que os alunos aprendem, importava adquirir segurança numa prática que elas já conheciam devido aos, pelo menos, 14 anos de aprendizagem por observação.

Para nós, educadoras de futuros professores, o desafio que se coloca é como implementar um programa voltado para a formação reflexiva numa perspectiva crítica que permita a incorporação da dimensão política do fazer pedagógico e do conceito de transformação social nela implícita. Em nosso modo de pensar, importa não só adotar a reflexão como modelo para o desenvolvimento profissional de futuros professores, mas também imprimir-lhe uma qualidade diferenciada, ainda na fase pré-serviço. Quanto mais soubermos como interagem as crenças e o conhecimento formal nas diversas etapas de atuação do futuro professor, mais poderemos contribuir para esse objetivo.

\section{Referências}

FEIMAN-NEMSER, S.; FLODEN, R. E. The cultures of teaching. In: WITTROCK, M. C. (Ed.). Handbook of research on teaching. New York: Macmillan Publishing Company, 1986. p. 505-526.

FEIMAN-NEMSER, S.; BUCHMANN, M.. Describing teacher education: a framework and illustrative findings from a longitudinal study of six students. The Elementary School Journal, v. 89, n. 3, p. 365-377, 1989.

FREEMAN, D. Language teacher education, emerging discourse, and change in classroom practice. In: FLOWERDEW, J.; BROCK, M.; HSIA, S. Perspectives on second language teacher education. City Polytechnic of Hong Kong, 1992. p. 1-21.

FULLER F. F.; BOWN, O. H. Becoming a teacher. In: RYAN, K. (Ed.). Teacher education. Chicago: University of Chicago Press, 1975. p. 25-52.

FURLONG, J.; MAYNARD, T. Mentoring student teachers: the growth of professional knowledge. London: Routledge, 1995.

KULCSAR, R.. O estágio supervisionado como atividade integradora. In: PICONEZ, S. C. B. (Coord.). A prática de ensino e o estágio supervisionado. 3.ed. Campinas:

Papirus, 1998. p. 63-74.

LORTIE, Dan C. Schoolteacher: a sociological study. Chicago: The University of Chicago Press, 1975.

MATEUS, E. F. A supervisão de estágio e a formação do professor de inglês. 1999. 155 fls. Dissertação (Mestrado em Educação) - Departamento de Educação, Universidade Estadual de Londrina, Londrina.

ORTENZI, D. I. B.G., MATEUS, E. F. e REIS, S. Alunas formandas do curso de Letras Anglo: escolhas, marcos e expectativas. IN: GIMENEZ, T. (Org.) Trajetórias na 
formação de professores de línguas estrangeiras. Inédito.

ORTENZI, D. I. B. G. A prática da reflexão num curso de formação de professores de língua estrangeira. 1997. 163fls. Dissertação (Mestrado em Lingüística Aplicada) Instituto de Estudos da Linguagem, Unicamp, Campinas.

PICONEZ, S. C. B. A prática de ensino e o estágio supervisionado: a aproximação da realidade escolar e a prática da reflexão. In: PICONEZ, S. C. B. (Coord.). A prática de ensino e o estágio supervisionado. 3.ed. Campinas: Papirus, 1998. p. 15-38.

PIMENTA, S. G. O estágio na formação de professores: unidade teoria e prática? 3.ed.

São Paulo: Cortez, 1997.

RICHARDS, J. C.; CROOKES, G. The practicum in TESOL. TESOL Quarterly, v. 22, n. 1, p. 9-27, March 1988.

TABACHNICK, R.; ZEICHNER, K. (Eds.). Issues and practices in inquiry oriented teacher Education. London: The Falmer Press, 1991 